\title{
The Scholarly Communication Process within the University Research Corridor (Michigan State University, the University of Michigan, and Wayne State University): A Case Study in Cooperation
}

\author{
TIMOTHY UTTER and ROBERT P. HOLLEY
}

\begin{abstract}
The growth of open access publishing, the development of institutional repositories, and the availability of millions of digitized monographs and journals are rapidly changing scholarly communication. This case study looks at the current and possible uses of these tools by Michigan's three largest universities: Michigan State University, the University of Michigan, and Wayne State University. The authors explore their usefulness in fostering collaboration within the University Research Corridor (URC), an alliance of the three universities, as a specific example of scholarly research collaborations. The paper also examines whether any shared use of these tools would further the related missions of the URC as well as their member universities and libraries toward the ultimate goal of helping the Michigan economy.
\end{abstract}

Keywords. Scholarly communication, scholarly publishing, open access, collaboration, University Research Corridor, institutional repositories 
Tim Utter is an Information Resources Specialist, Senior, Map Library, Harlan Hatcher Graduate Library, University of Michigan, 920 N. University Ave., Ann Arbor, MI, 48109-1205 (tutter@umich.edu). He is working on his Masters in the Library and Information Science Program at Wayne State University, Detroit, MI. (E-mail: tutter@umich.edu).

Robert P. Holley is Professor, Library and Information Science Program, Wayne State University, Detroit, MI, 48070. (E-mail: aa3805@wayne.edu). 


\section{Introduction: Recent Changes in Scholarly Communication}

Scholarly communication has reached a tipping point. How will the many changes affect the University Research Corridor, created by Michigan State University, the University of Michigan, and Wayne State University in November 2006 to foster cooperation among the three largest research universities in Michigan? What will be the effects upon their research libraries? Many recent events promise significantly increased open access to scholarly research. The Google Book Search Project has reached a proposed settlement in the class action suit with the Authors Guild and the Association of American Publishers (AAP) that will allow full-text access to millions of scanned books including many that are still in copyright. (Google, 2008) The Internet Archive has scanned its $1,000,000^{\text {th }}$ item. (Internet Archive, 2008) The National Institutes of Health Public Access Policy guarantees public access to NIH funded research. (National Institute of Health, 2008) The HathiTrust Digital Library, a digital non-commercial repository with current holdings of nearly 2.5 million volumes, has the mission to "contribute to the common good by collecting, organizing, preserving, communicating, and sharing the record of human knowledge.” (HathiTrust Digital Library, 2008) Harvard University’s Faculty of Arts and Sciences voted to become the first university to adopt an open access policy for its faculty members' research publications. (Harvard Magazine, 2008) The European Research Council requires that all peer-reviewed publications from ERC funded research must be made available through open access. (University of Illinois at Urbana Champaign Library, 2008) Thousands of open access journals are available from the Directory of Open Access Journals. (Lund University, 2008) 
The proposed settlement between Google and the Authors Guild and the AAP is especially historic and will likely be seen as a turning point in public or "free" access to digital information. The Google Book Search Project is one of many initiatives that are changing the way scholars find information and may signal the beginning of the end for our current way of organizing and packaging information both physically and mentally. How scholars think about and access information is changing. Will the "journal" as an organized collection of subject specific articles be necessary? Organized collections of subject specific information will of course still be useful but what is changing is who organizes the information into a collection and who owns it. Researchers will be able to make their own collections of information packets and organize them together as they see fit while respecting the rights and wishes of the copyright owners. Copyright tools such as Creative Commons are making it much easier to know the extent of copyright limitations as defined by the copyright owner. (Creative Commons, 2008)

\section{The University Research Corridor}

Our intent is to discuss these areas of scholarly communication and research with specific examples of how they are or could be used. We will also explore their usefulness as a collaborative tool that is or could be applied within the University Research Corridor (URC), an alliance of three largest research universities in Michigan, as a specific example of any scholarly research collaborations. We would also like to determine if any collaborative use of these tools would further the related missions of the URC as well as their member universities and libraries toward the ultimate goal of helping the Michigan economy. Many of the examples that we use are local to Michigan, but we believe that 
they provide an interesting slice of what is happening nationally in the area of scholarly communication. The three members also provide a relatively varied sampling of size, expenditure, and funding for large academic libraries. The URC is made up of the three leading research institutions in the State of Michigan: the University of Michigan, Michigan State University and Wayne State University. They rank $6^{\text {th }}, 49^{\text {th, }}$ and $69^{\text {th }}$ respectively for total library expenditures for U.S. and Canadian university research libraries. (Chronicle of Higher Education, 2008) The URC was formed by the three universities in November 2006, but it has evolved from partnerships that have existed for many years, including the Life Sciences Corridor that was created in 1999. The URC's aim is to "leverage their collective assets, encourage collaboration, and increase business partnerships with an overarching goal of promoting statewide economic development." (Wayne State University, 2007) A 2008 study shows that the URC members have an economic impact of $\$ 13.3$ billion, have operational expenditures of $\$ 6.5$ billion, spend $\$ 1.38$ billion on research, generate 69,285 jobs, and educate 135,816 students--more than any comparable research and development cluster. (University Research Corridor, 2008) The University of Michigan spent $\$ 823$ million on research in 2007 and ranked second in the nation according to the National Science Foundation survey which is based on 2005 data. (University of Michigan, 2007) The URC is Michigan's unique version of the North Carolina Research Triangle and is at the heart of Michigan's evolution from a manufacturing to a knowledge based economy. An example of the changing nature of the local economy is the $\$ 550$ million award to Michigan State University from the Department of Energy to build the Facility for Rare Isotope Beams. The facility is 
expected to ultimately bring in $\$ 1$ billion in economic activity and around 400 jobs.

(MSU News, 2008)

\section{Digitization Initiatives}

The University of Michigan is one of the original partners in the Google Book Search Project. The Google Books Library Project involves the digitization of several million volumes from some of the largest libraries around the world. Full text viewing and downloading is available for out-of-copyright works. For in-copyright works, Google shows a few sentences where the search term appears. Google also partners with publishers to digitize and display the full content of their works. (Google, 2008) Needless to say, the availability of full-text online access to millions of books is changing how scholars and researchers search for and access library content. As part their agreement with Google, the University of Michigan receives a copy of the files of all the incopyright as well as out-of-copyright items that have been digitized from their library. The recent proposed settlement will remove the threat of legal challenges to the University of Michigan's keeping the files for the materials that are still under copyright protection.

The HathiTrust Digital Library (http://www.hathitrust.org/) includes all the Google Book Project files owned by HathiTrust partner institutions as well as the thousands that the institutions have digitized themselves. The current partners of the HathiTrust are the members of the Committee on Institutional Cooperation (CIC - Big Ten universities and the University of Chicago), the eleven university libraries of the University of California system, the California Digital Library, the University of Illinois 
at Chicago, and the University of Virginia. This repository currently contains over 2.5 million volumes and over 800 million pages with monthly additions of about 300,000 volumes. Currently approximately 16 percent of the volumes are in the public domain. (HathiTrust Digital Library, 2008) Materials in the public domain are freely available online. According to John Wilkin, executive director of the Trust: "Before this collaboration the collections in each library existed in isolation. Now we are bringing them together, pooling resources and eliminating redundancies, and producing a valuable research tool that will be greater than the sum of its parts." (Schaffhauser, 2008) The key word is "library." The partners are dedicated to creating the largest digital research library anywhere and to making it available to everyone for free. HathiTrust's emphasis is on providing access, organization, and long term preservation of information to meet the needs of scholars and other members of the academic community. The HathiTrust will eventually have its own search interface. Currently the University of Michigan and some of the other partners of the Trust have bibliographic records for public domain materials of the HathiTrust in their local catalogs. (HathiTrust Digital Library, 2008) The University of Michigan also has an in-house digitization unit that digitizes about 5,000 volumes per year. (Google Book Search Library Partners, 2008)

The Michigan State University Libraries are a member of the HathiTrust and CIC. It is likely that some items from Michigan State University Libraries will be digitized as part of a probable agreement between Google and CIC. (C. Haka, personal communication, January 8, 2009) Michigan State University is currently digitizing portions of their special collections. These items are available through the Digital and Multimedia Center (http://digital.lib.msu.edu/), which contains about 13,000 records and 
is mainly made up of digital images of items in their Special Collections division. Of note is the G. Robert Vincent Voice Library that consists of over 15,000 sound files consisting of 40,000 hours of analog recordings, many of which are now available as streamed audio files. An added benefit is that all the works are in the public domain. Collections currently online include Shaping the Values of Youth: Sunday School Books in 19th Century America; and Feeding America: The Historic American Cookbook Project. (Michigan State University Libraries, 2007) The Michigan State University Libraries plan to expand their digitization efforts.

Wayne State University Libraries' extensive digital collections (http://www.lib.wayne.edu/resources/digital_library/) are managed by the New Media + Information Technology department and are part of the library collections. According to Dr. Sandra Yee, Dean of the Wayne State University Libraries, "The collections focus mainly on Detroit history and culture and include an extensive image collection of costumes, furniture, art and photographs from the Detroit News Photo Archives. Primary partners in the creation of these digital projects include WSU departments, The Henry Ford, The Detroit Historical Museum and the Reuther Library and Labor Archives as well as several other museums and libraries." (personal communication, January 12, 2009)

\section{Open Access}

Open access primarily refers to scholarly works that are online, digital, freely, available at no cost to the user, and available with few or no copyright restrictions. According to the Budapest Open Access Initiative, the requirements of open access are: 
"free availability on the public Internet, permitting any users to read, download, copy, distribute, print, search, or link to the full texts of these articles, crawl them for indexing, pass them as data to software, or use them for any other lawful purpose, without financial, legal, or technical barriers other than those inseparable from gaining access to the Internet itself. The only constraint on reproduction and distribution and the only role for copyright in this domain should be to give authors control over the integrity of their work and the right to be properly acknowledged and cited." (Suber, 2007)

Under the two other main declarations on Open Access, the Bethesda Statement on Open Access Publishing and the Berlin Declaration on Open Access to Knowledge in the Sciences and Humanities, the copyright holder also gives consent to users "to distribute and make derivative works". (Suber 2007) In the traditional scholarly publication model, authors are usually not paid for their published research and most often give up copyright to the publisher. Open access does not require that copyright holders give up all of their rights it allows the author to retain some aspects of copyright such as the right to block "mangled or misattributed copies". (Suber, 2007) Open Access is compatible with peer review. Open Access archives and repositories do not perform peer review but merely host their contents for free access. Institutional repositories and archives usually include scholar's preprints at the very least though some journals allow repositories to make the published post-prints available. 
Many Open Access journals are peer reviewed even if their contents are freely available. The Directory of Open Access Journals (DOAJ) (http://www.doaj.org/doaj?func=home) has over 3,700 journal titles and over 200,000 articles (DOAJ, 2008). Several hundred of their titles are peer-reviewed. (University of Colorado Boulder Libraries, 2008) The DOAJ states that "for a journal to be included it should exercise quality control on submitted papers through an editor, editorial board and/or a peer-review system". (Lund University, 2008) They are, not surprisingly, a good source of information on open access journals. Of course providing open access is not free. Several funding models exist to pay the costs of peer review, editing, and hosting content. The possibilities include fees paid by the author, by the author's institution either by unit or institution based funding, by the research funding source, or by foundations to name a few options. The models are evolving and what works best depends on each institution's circumstances. (Earlham College, 2008) One thing for certain, current serial publishing pricing models are not working for the academy. Open access journals will save money by publishing online only and by using shared technology. The scholarly communication system has reached the point where most, if not all academic libraries, understand that they must transition from purchased access to open access if they are to maintain desired service levels. The transition requires that academic authors understand the importance of publishing in an open access environment. There is some evidence that open access articles get cited more often and that open access "accelerates the pace at which science develops." (Lewis, 2007) The main stumbling block is the issue of academic reward for such publishing. Universities can help reduce the costs of scholarly communication by explicitly including statements in their tenure and promotion policies 
that the weight of peer reviewed open access journals should be determined in the same way as for print journals.

Open access furthers the mission of the academy by promoting scholarship and scholarly inquiry and by providing access more efficiently than do print journals and monographs. Open access gives some control of scholarly communication back to the academy. Teaching and learning will also benefit from open access. The library is the most qualified and appropriate host of institutional open access materials such that a library managed institutional repository is the most logical place to archive these materials.

\section{Institutional Repositories}

Institutional repositories are "digital collections that capture and preserve the intellectual output of university communities - respond to two strategic issues facing academic institutions: 1) they provide a central component in reforming scholarly communication by stimulating innovation in a disaggregated publishing structure; and 2) they serve as tangible indicators of an institution's quality, thus increasing its visibility, prestige, and public value." (Crow, 2002) Institutional repositories are similar to digital collections except that they often include more of the output of the institution including unpublished papers, preprints, administrative papers, dissertations, and many other types of documents.

Wayne State's institutional repository (http://digitalcommons.wayne.edu/about.html) uses Digital Commons software and is hosted by bepress, the service provided by the Berkeley Electronic Preess, which is used 
by over eighty institutions. Digital Commons is a hosted system that allows for easy management of the system. Uploading data is the the only main responsibility of the institution. Searching is straighforward; users can browse content by department, academic discipline, or author within the local repository as well as within all other members repositories. Members include the entire University of California system; Boston College; Purdue; the Universities of Massachusetts, Nebraska, and Iowa; Carnegie Mellon University and many others. Digital Commons also comes with EdiKit, a peer review workflow application. (Berkeley Electronic Press)

The University of Michigan's institutional repository is Deep Blue (http://deepblue.lib.umich.edu). According to its Web page, the benefits of archiving documents in Deep Blue are: visibility, permanence, comprehensiveness, safe storage, control over access, and context. (University of Michigan Library, 2008) These advantages offer a good description of the ideal qualities of a good institutional repository. Deep Blue uses DSpace, an open-source software developed at MIT, which claims to have the largest number of repository users at over 250 . Most users are academic libraries.

According to Jim Ottaviani, coordinator of Deep Blue: “At least 80\% of all access to Deep Blue comes through Google and Google Scholar." Based on this statement, there may not really be a need for institutions to create separate complex searching algorithms and duplicate what Google's already does so well. One problem, however, may be those searches that retrieve so many entries that the documents in the institutional repositories are placed too far down in the results list by the Google algorithm. Thus, the number of successful searches does not necessarily mean that researchers are finding what they need 
from the Google search engine. On the other hand, institutions are getting good at creating tagging, meta-tagging, and metadata that helps to increase the precision of search results. Unfortunately, according to Kat Hagedorn, Metadata Harvesting Librarian at the University of Michigan Libraries, Google ignores the use of metadata in their indexing so that they have not gotten better at handling structured data that is contained in fixed fields within a record. (personal communication, December 22, 2008)

The Open Archives Initiative has developed standards that promote interoperability if data creators conform to the metadata harvesting protocol of the Open Archives Initiative - Protocol for Metadata Harvesting (http://www.openarchives.org/pmh). OAI-PMH is a basic protocol that provides easy use by participants and is not intended as a replacement for other protocols such as Z39.50. (Open Archives Initiative, 2008) Most institutional repositories use the same base structure and metadata fields though there is no one standard for metadata for data within institutional repositories. Deep Blue uses Dublin Core and Dublin Core Qualified but requires just title, author, and date to make it easier for faculty to submit their data. Most records include additional metadata; many include abstracts.

Institutional holdings are searchable from anywhere and become part of the larger pool of similar data. Interoperability allows data harvesters such as OAIster, which describes itself as a "union catalog of digital resources," (OAIster, 2008) to harvest millions of records. The Andrew H. Mellon Foundation originally funded this tool that is now supported by the University of Michigan Libraries. OAIster uses the OAI-PMH protocol to harvest institutional repositories and is very good at harvesting data from the "deep web" by finding records that are hidden behind Web scripts that cause common 
search engines to miss them. OAIster currently provides access to over 19 million records from 1,000 repositories, and the search results in OAIster allow the user to access the digital objects held by those institutions. (OAIster, 2008) Why not just use Google or Google Scholar as the "main" search tool? One reason to use a data harvester such as OAIster instead of Google is because, according to a study done by Kat Hagedorn and Joshua Santelli, a computer programmer at the University of Michigan, Google is not indexing Web URL's that are hidden because the institutions have not created static pages for the records. Of the 147,305 sample URL's tested, a Google search did not find $55.65 \%$ of the records. (Hagedorn, 2008) Furthermore, it would be possible to use OAIster to find which records from the search results are from a particular institution's repository. Users do not, however, usually search for data from specific institutions since they most often do not care about the source of the information or data as long as the documents are from reputable repositories or are peer reviewed.

The Michigan State University Libraries do not have an official institutional repository. As mentioned earlier, their Digital and Multimedia Center comes the closest to providing this service.

Institutional repositories and data harvesters are wonderful tools that are changing scholarship. Our experience has been that data harvesters are easy to use and offer great possibilities for research and document retrieval. Institutional participation rates are about 15\%. (Harvard Magazine, 2008) With mandatory archiving by Harvard's Faculty of Arts and Sciences, participation rates should increase greatly at other institutions as institutional repositories become more accepted in the academy. 


\section{Scholarly Publishing Offices}

We are using the term scholarly publishing offices to refer to offices within the university whose focus is to publish the scholarly content of the university and/or any content from the library's digitization initiatives. This activity would most likely be done by a digital library or digital initiatives office though the institution's university press could provide this service. At the University of Michigan, the Scholarly Publishing Office (SPO) ( http://www.lib.umich.edu/spo ) "experiments with the possibilities of library-based publishing. Electronic publishing is still in its early stages and the role of publisher is a new one for libraries, and SPO is still a young organization. In short, we are working in an area where there is much to learn. We share our questions and findings by reporting widely on these activities through conference papers, publications and reports on this web site. We welcome conversations with colleagues from peer institutions who are engaging in similar experiments." (Scholarly Publishing Office, 2008) The SPO is an alternative to traditional university presses and commercial publishers. Among other services, SPO publishes fifteen mostly open-access electronic journals, a monograph series, and digital special projects including online exhibits. SPO also provides hosting services for large subscription-based resources. Finally, SPO runs the new print-ondemand program with its new Espresso Book Machine, has over 9000 books for sale on Amazon, and has a joint project with the University of Michigan Press called digitalculturebooks ( http://www.digitalculture.org/) to publish open access and print books focused on the social and cultural impacts of new media. (Scholarly Publishing

Office, 2008) 
Neither Wayne State nor Michigan State University has an electronic scholarly publishing office. They both have a large and well regarded university presses: Michigan State University Press (http://msupress.msu.edu) and Wayne State University Press (http://wsupress.wayne.edu/index.php).

\section{Potential Models for Shared Services in the URC}

In 1992, the three university libraries joined together to form the Michigan Research Libraries Triangle (MRLT) with the mission: "to meet the educational and information needs of students, faculty, and researchers. Given the funding challenges facing academic libraries today, the MRLT works to avoid unnecessary costs such as those associated with the duplication of library materials and to improve the quality of services offered to its campuses." Some of their efforts have included access to each other's online catalogs in 1994, reciprocal interlibrary loan and document delivery, and the ability of faculty and graduate students to borrow materials from any of the three systems. ( Information Today, 1994) The 1994 initiative to link the three libraries

received $\$ 300,000$ from the U.S. Department of Education Title II-A Program. Since the URC has joined together as a research entity, their libraries could best serve the alliance by doing what they can to support effectively the research needs of the URC including some joint programs. As a first step, more communication between all levels of staff members at the respective libraries would help coordinate initiatives, foster cooperation, and avoid duplication. While the deans/directors of the three libraries already communicate regularly, extending contacts to the upper and mid-levels of staff would be beneficial. Such communication could lead to a greater awareness of the services that 
each library provides and could translate to something as simple as a link to each others' lists of open access documents and resources or to something as complex as a large joint library project.

It is important to spend resources wisely by not duplicating what is already being done well and by not doing jointly what is best done alone. Additional large joint digitization projects are most likely not needed. The Google Books project, the HathiTrust, and the Internet Archives currently meet most needs and will likely continue to meet them in the future. As we mentioned earlier, Google will likely digitize some items in the Michigan State University Libraries' collections as part of a probable agreement between Google and CIC. Both Michigan State University and Wayne State University are digitizing portions of their special collections so that it might make sense to share some equipment to help make sure that these two unique collections are digitized. In many ways, the best solution would be for Wayne State University to join the CIC because it is a large respected research university located in Big Ten country, but doing so would most likely lead to too many requests from similar institutions. If Wayne State University wanted to digitize selected parts of its collection on its own, Brewster Kahle, Internet Archive, estimates the Internet Archive's cost of scanning, storing, and serving at $10 \notin$ per page. (Kahle, 2008)

According to Dr. Yee Wayne State has made other resource sharing arrangements, "including being one of the early university adopters of MeLCat, (Michigan Electronic Library Catalog) and the MeLCat resource sharing option and [by] joining ArticleReach Direct, the group of ARL libraries using Innovative's ArticleReach 
software to provide patron initiated, non-mediated document delivery." (personal communication, January 7, 2009)

Sharing open access resources is fairly straightforward. It could be done with links or by a shared meta-search that searches just the institutional repositories at these three universities since this solution is technically straightforward. Generally, however, researchers would not prefer to search only for records from local repositories. In addition, the broad searching abilities of data harvesters such as OAIster make the need for local repository search features less important. A very positive development for URC cooperation would be for Michigan State University to create an institutional repository since they do not have one at this point.

While it would be very beneficial for URC to follow Harvard and have a mandatory deposit of faculty publishing into the institutional repositories, requiring faculty to do so would require changes at all three institutions where faculty and staff currently hold copyright to their scholarly publications. At the University of Michigan, rights to a publication are technically owned by the University; but, following the principles of academic freedom, the rights are turned over to the author. There are some circumstances under which the university retains copyright, including if the work is created with the support of external grants or special university funding or help. A faculty vote similar to Harvard's would most likely be needed to mandate deposit of faculty publishing. (University of Michigan, 2002) Wayne State University's copyright policy states that "[g]enerally, the members of the University faculty and staff shall retain all rights to copyright in published works which they have authored as a part of their traditional scholarly pursuits." (Wayne State University, Board of Governors, 1984) 
Requiring faculty to deposit their work in an institutional repository would most likely require a change to the AAUP contract. In a similar fashion, "MSU follows standard academic practice in disclaiming ownership of, and royalties proceeding from, traditional academic works (books, essays, works of art, musical compositions and recordings, and the like), unless one or more 'Special Circumstances' exist.” (MSU Human Resources, 2005) As at the University of Michigan, faculty support would be crucial in making a change to mandatory deposit of faculty publishing in an institutional repository.

Other possible cooperative ventures include a meta-search of the three online catalogs though software issues might make this enhancement difficult. Since the Michigan Research Libraries Triangle cooperative agreement already allows faculty and graduate students at the three institutions to check out books from each other, the catalog "meta-search" might create more usage. The HathiTrust may eventually be at least a partial solution for sharing records. WorldCat allows the "meta-search" to some degree, especially since Michigan holdings are shown first for searches with a large number of holdings. Electronic resources would not be easy to share because of licensing. Finally, a shared off-site book storage and delivery system could be useful as the three URC libraries become less dependent on their print collection with the availability of digital copies from Google, the HathiTrust, and other sources.

The most useful joint venture for the URC libraries might be a shared scholarly publishing office. The University of Michigan has established a good model for this activity so that turning this office into a joint initiative would seem "easy" to do and would presumably be more efficient and beneficial to the URC than establishing new offices at Wayne State University and Michigan State University. Most importantly, this 
kind of "in-house" publishing of scholarly research and reports would be very beneficial to the goals of the URC. It may even be possible to have a for-profit business model to help the start-ups that the URC is expected to create. Another part of this cooperative initiative might be a joint copyright office that would be extremely useful to faculty and researchers as well. Overall, establishing a cooperative scholarly publishing office would be the most effective and efficient of the previously discussed joint options. Scholarly publishing and promotion of research from the three universities seems to us to be the best fit for the URC's strategic goals.

We believe that this model could work for other research alliances. Each would have different needs to fill and use different tools and services to reach these goals. One of the wonderful things about technology is that it does not have to be an all or nothing situation. Institutions can share some services when it is beneficial for them and avoid sharing others when it is not.

\section{Conclusion}

The combined assets of the libraries within the University Research Consortium are capable of meeting the needs and furthering the goals of the URC. The libraries can play an active role in the URC's success. We believe that they have much to offer in establishing the vision of the URC as well. In general, universities will be well served by the following initiatives:

- the library has an open access institutional repository to host and archive the university's research and other documents; 
- the university makes available and promotes open access scholarly resources; and

- $\quad$ the university provides some scholarly publishing and copyright assistance.

Increased publishing in an open access environment will further research, give authors more control over their works, and make finding information much easier with data harvesting tools such as OAIster.

The URC promotes the economic opportunities and partnerships based on the research done at the universities. It would benefit all parties to look at what they can do to further the needs of their users and of the URC collectively. The actions that they take will be important to the local, national, and international communities as these actions help create economic benefits for the region through the direct activities of the three universities as well as through new business enterprises that the URC helps spawn. Carefully considered cooperative initiatives by the three universities and their libraries will help make real the vision of the URC " $[\mathrm{t}] \mathrm{o}$ unite and lead, playing a key role in creating a vibrant Michigan economy that leverages the intellectual capital of its three public research universities, to work proactively to attract the knowledge economy businesses that can find the research activity that feeds new enterprise, educates the workforce and plants the seeds for the new industries of tomorrow." (University Research Corridor, 2008) 


\section{References}

Berkely Electronic Press. (2008). Retrieved November 8, 2008, from Berkeley Electronic Press: http://www.bepress.com/ir/

Chronicle of Higher Education. (2008, August). Library Investment Index. Retrieved November 6, 2008 , from Chronicle of Higher Education: http://chronicle.com/free/almanac/2008/nation/nation_index.htm

Creative Commons. (2008). Retrieved December 26, 2008, from Creative Commons: http://creativecommons.org/

Crow, R. (2002). The Case for Institutional Repositories: A SPARC Position Paper. Retrieved November 2, 2008, from SPARC: http://www.arl.org/sparc/bm doc/ir_final_release_102.pdf

Directory of Open Access Journals. (2008). Retrieved November 8, 2008, from Directory of Open Access Journals: http://www.doaj.org/

Earlham College. (2008). Budapest Open Access Initiative: Frequently Asked Questions. Retrieved November 3, 2008, from http://www.earlham.edu/ peters/fos/overview.htm

Google. (2008, October 28). New Chapter for Google Book Search. Retrieved December 26, 2008, from The Official Google Blog: http://googleblog.blogspot.com/2008/10/new-chapter-for-google-booksearch.html

Google. (2008). Google Book Search Library Partners. Retrieved December 27, 2008 from http://www.google.com/googlebooks/partners.html 
Hagedorn, K. and Santelli, Joshua. (2008, July/August). Google Still Not Indexing

Hidden Web URL's. Retrieved November 5, 2008, from D-Lib Magazine: http://www.dlib.org/dlib/july08/hagedorn/07hagedorn.html

Harvard Magazine. (2008, May/June). Open Access. Retrieved November 9, 2008, from Harvard Magazine: http://harvardmagazine.com/2008/05/open-access.html

Hathi Trust Digital Library. (2008). Retrieved November 6, 2008, from http://www.hathitrust.org/

Information Today. (1994). Michigan Research Libraries Triangle Reports Progress in Second Year. Information Today, 48.

Internet Archive. (2008). Retrieved December 26, 2008, from Internet Archive: http://www.archive.org/index.php

Kahle, B. (2008, October 22). John Seely Brown Symposium. Ann Arbor, MI.

Lewis, D. (2007, September). A Strategy for Academic Libraries in the First Quarter of the 21st Century. College of Research Libraries , pp. 418-434.

Lund University. (2008). Retrieved December 26, 2008, from Directory of Open Access Journals: http://www.doaj.org/

Michigan State University Human Resources Department. (2005). Development of Copyrighted Materials. Retrieved January 6, 2009, from http://www.hr.msu.edu/HRsite/Documents/Faculty/Handbooks/Faculty/Research CreativeEndeavor/vi-copyrightedmaterial.htm

Michigan State University Libraries. (2007). Digital and Multimedia Center. Retrieved November 6, 2008, from http://www2.lib.msu.edu/branches/dmc/index.jsp 
Michigan State University News. (2008). MSU Selected as Site for $\$ 55$ million Facility for Rare Isotope Beams. Retrieved December 27, 2008, from MSU News: http://news.msu.edu/story/5768

National Institute of Health. (2008). Public Access. Retrieved November 3, 2008, from National Institute of Health: http://publicaccess.nih.gov/

Oaister. (2008, October 31st). Retrieved November 5, 2008, from http://www.oaister.org/ Open Archives Initiative. (2008). Retrieved November 8, 2008, from Open Archives Initiative: http://www.openarchives.org/

Schaffhauser, D. (2008, October 15). Research Libraries Collaborate on Shared Digital Repository . Retrieved November 6, 2008 , from Campus Technology: http://campustechnology.com/articles/68499/

Scholarly Publishing Office. (2008). Scholarly Publishing Office. Retrieved November 7 , 2008, from Scholarly Publishing Office: http://www.lib.umich.edu/spo/

Suber, P. (2007). Open Access Overview. Retrieved November 3, 2007, from Earlham College: http://www.earlham.edu/ peters/fos/overview.htm

University of Colorado Boulder Libraries. (2008). Dean's Office - Peer Reviewed Journals. Retrieved December 26, 2008, from http://ucblibraries.colorado.edu/dean/peer_reviewed.htm University of Illinois at Urbana Champaign Library. (2008, January 16). Scholarly Communication. Retrieved December 26, 2008, from University Library: http://www.library.uiuc.edu/blog/scholcomm/archives/2008/01/open_access_man. html

University of Michigan. (2002). University of Michigan Standard Practice Guide. 
Retrieved January 6, 2009, from http://spg.umich.edu/pdf/601.03-2.pdf

University of Michigan. (2007). Financial Report, 2007. Retrieved November 9, 2008, from

http://www.finops.umich.edu/FormsRepoarts/Reports/2007/highlights/research.ht $\mathrm{ml}$

University of Michigan. (2007). Copyright at the University of Michigan. Retrieved December 27, 2008, from http://www.copyright.umich.edu/official-policy.html University of Michigan Library. (2008). Retrieved November 4, 2008, from Deep Blue: http://deepblue.lib.umich.edu/

University Research Corridor (2008). URC - Economic. Retrieved November 6, 2008, from http://www.urcmich.org/economic/

University Research Corridor. (2008). URC - University Research Corridor: Empowering Michigan. Retrieved November 4, 2008, from http://www.urcmich.org/

Wayne State University. (2007, May 5). Public Relations. Retrieved November 6, 2008, from http://www.media.wayne.edu/2007/05/31/michigans-assets-for-economicgrowth-stand-among-the-nations-best-presidents-offer-full-resources-to-jumpstart-michigans-economy

Wayne State University Board of Governors. (1984). Wayne State University Statutes. Retrieved January 6, 2009 from http://bog.wayne.edu/code/2_41_04.php 